\title{
Cine, Moda, Cuerpo, Arte y Diseño: La moda en el cine Proyecto de Investigación $\mathrm{N}^{\circ} 17.1$ \\ Equipo de Investigación ${ }^{(1)}$
}

Patricia Doria

por Facultad de Diseño y Comunicación, Universidad de Palermo (ARG)

Denise Trindade

por Universidade Estácio de Sá (BRA)

Beatriz Ferreira Pires

por Escola de Artes, Ciências e Humanidades, Universidade de São Paulo

EACH-USP (BRA)

Resumen: El Proyecto de Investigación 17.1 explora distintas producciones vinculadas con énfasis en el cine, como otra forma de narrar y temporalizar la moda. El cine, como expresión de la cultura de masas, siempre ha sido representación de imaginarios y aspiraciones diversas, donde la moda, en tanto fenómeno social y cultural, no ha quedado exenta de su influencia. Propone despertar la conciencia de la relación entre la moda y el cine, y generar nuevos interrogantes sobre estas áreas disciplinares, el vínculo con el sistema de significaciones, en el análisis semántico y sintáctico que crea sentido mediante el vestuario. Extender el análisis lingüístico al conjunto de los fenómenos culturales principalmente sobre la moda y los signos sociales que hacen posible su decodificación a través del cine. De este modo, vestuarios inspiradores, simbologías y mensajes implícitos se dan cita en films que reflejan valores, sentidos, rasgos de épocas y situaciones ancladas en la memoria colectiva. Se analiza el fenómeno mediante un recorrido metodológico plural y multidisciplinario, a partir de un corpus fílmico, que establece su correlato con el sistema de la moda de los siglos XX y XXI.

Palabras clave: Audiovisual - Cine - Corporal - Moda - Personajes - Seducción - Significado.

[Resúmenes en inglés y portugués en la página 256]

${ }^{(1)}$ Los CVs del Equipo de Investigación pueden consultarse en el Capitulo Directores de Líneas y Coordinadores de Proyectos de esta misma Edición. 


\section{Acerca del Proyecto 17.1}

\section{Cine, Moda, Cuerpo, Arte y Diseño: La moda en el cine}

El Proyecto 17.1 Cine, Moda, Cuerpo, Arte y Diseño: La moda en el cine, explora distintas producciones vinculadas con énfasis en el cine, como otra forma de narrar y temporalizar la moda. Pretende impactar en la actualización de los contenidos dictados en las carreras de grado y posgrado, pudiendo contribuir con la capacitación profesional de los diseñadores para una reflexión sobre su propia práctica.

Se acordó entre la Universidad de Palermo, la Universidade Estácio de Sá (BRA) y Escola de Artes, Ciências e Humanidades, Universidade de São Paulo EACH-USP (BRA) avanzar en una investigación en la que participan académicos de las tres Instituciones, con la coordinación compartida de Patricia Doria (UP), Denise Trindade (Universidade Estácio de Sá, Brasil) y Beatriz Ferreira Pires (Escola de Artes, Ciências e Humanidades, Universidade de São Paulo EACH-USP, Brasil), con el fin de generar un corpus sólido de conocimientos sobre la relación cine, moda, cuerpo y arte. Se desarrolla a través de la articulación de producciones teóricas de profesionales de la moda, la imagen y las tendencias convocados a reflexionar sobre diversas dimensiones del campo en estudio.

Las reflexiones y los resultados obtenidos en el Proyecto 17.1 Cine, Moda, Cuerpo, Arte y Diseño, se continúan desarrollando en el Proyecto 17.3 La Moda en su Laberinto, y guardan relación con el 17.2 Comunicación e Imagen personal $360^{\circ}$ y $17.4 \mathrm{La}$ Imagen personal frente a los nuevos desafíos 2020, en el marco de la misma Línea de Investigación y bajo la misma Directora Patricia Doria.

Sus principales objetivos son:

- Extender el análisis lingüístico al conjunto de los fenómenos culturales principalmente sobre la moda y los signos sociales que hacen posible su decodificación a través del cine.

- Identificar de qué forma la representación del cuerpo ha constituido un elemento clave, para la comunicación, la moda y las tendencias del arte y el diseño de indumentaria.

- Descubrir y analizar las distintas variables del sistema de la moda, el vestuario, y del cuerpo vestido, presentes en las intersecciones de la Moda, las imágenes audiovisuales del Cine y los medios de comunicación.

- Problematizar y teorizar el sistema de significaciones socio-culturales-epocales presentes en los discursos de moda, indumentaria y cuerpo que surgen de la lectura de grandes films, en la búsqueda de creación de sentido cultural, social, cronológico y de época. 


\section{Acerca de la Línea 17}

Imagen, Moda y Tendencias dirigida por Patricia Doria se desarrolla de manera ininterrumpida desde 2015 en la Facultad de Diseño y Comunicación (UP, Argentina), e incluye hasta el momento cuatro proyectos finalizados el 17.1 Cine, Moda, Cuerpo, Arte y Diseño coordinado por Patricia Doria (UP), Denise Trindade (Universidade Estácio de Sá, Brasil) y Beatriz Ferreira Pires (Escola de Artes, Ciências e Humanidades, Universidade de São Paulo EACH-USP, Brasil), el 17.2 Comunicación e Imagen personal $360^{\circ}$ coordinado por María Pia Estebecorena y Susy Inés Bello Knoll (UP y AICI), el 17.3 La Moda en su Laberinto coordinado por Patricia Doria (UP), y el 17.4 La Imagen personal frente a los nuevos desafíos 2020 coordinado por María Pía Estebecorena (UP y AICI).

\section{Mapa de Áreas y Proyectos}

El Proyecto 17.1 se vincula con todas las carreras de grado y posgrado correspondientes a la Facultad de Diseño y Comunicación, y está claramente enlazado a las carreras de indumentaria, moda e imagen: Comunicación de Moda, Diseño de Moda, Fotografía de Moda, Marketing de la Moda, Moldería \& Confección y Producción de Moda. Guarda relación con la serie de proyectos de la Línea 12. Nuevos paradigmas en la enseñanza de la moda y el diseño y en la Línea 5. Cuerpo y Vestuario.

\section{Productos y Resultados}

\section{a)- Publicaciones}

Cuaderno del Centro de Estudios de Diseño y Comunicación No58. (2016) Cine y Moda. Cuerpo, Arte y Diseño. Coordinación Patricia Doria Denise Trindade y Beatriz Ferreira Pires. Facultad de Diseño y Comunicación Año XVI, Buenos Aires, Argentina. ISSN: 1668-0227. Esta publicación documenta y comunica los resultados alcanzados en el proyecto de investigación 17.1 Cine, Moda, Cuerpo, Arte y Diseño, y a continuación se detallan los autores y artículos contenidos en ella:

Doria, Patricia (2016) Prólogo Universidad de Palermo (Pp. 13 a 15)

Carlos, Matilde (2016) Moda en cine: signos y simbolismos (Pp. 17 a 22)

Ceccato, Daniela (2016) Cortos de moda, un género en auge (Pp. 23 a 34)

Doria, Patricia (2016) Brillos y utopías (Pp. 35 a 41)

Fiorini, Verónica (2016) Moda, cuerpo y cine (Pp. 43 a 50)

Garizoain, Cecilia (2016) De la pasarela al cine, del cine a la pasarela. El vestuario y la moda en el cine argentino hoy (Pp. 51 a 59)

Orta, Matías (2016) Moda fantástica (Pp. 61 a 78)

Roffe, Solana (2016) Vestuario de cine: el relator silencioso (Pp. 79 a 86)

Veneziani, Marcia (2016) Moda y cine: entre el relato y el ropaje (Pp. 87 a 98) 
Acar, Lucía (2016) La seducción del cuerpo vestido en La fuente de las mujeres (Pp. 99 a 104)

di Cola, Flávio (2016) Moda y autenticidad histórica en el cine: nuevos ecos de la escuela viscontina (Pp. 105 a 113)

Monteiro, Eliana (2016) El amor, los cuerpos y las ropas en Michael Haneke (Pp. 115 a 122)

Trindade, Denise (2016) Vestes del tiempo: telas, movimientos e intervalos en la película Lavoura Arcaica (Pp. 123 a 130)

Villaça, Nizia (2016) Almodóvar: cineasta y diseñador (Pp. 131 a 139)

Mazás, Fernando (2016) El cine come metalenguaje. Haciendo visible el código de la moda (Pp. 141 a 151)

Doria, Patricia (2016) Prólogo Universidad de Palermo (Pp. 153 a 155)

Cornejo, Sandra (2016) Cuerpo, imagen e identidad. Una relación (im)perfecta (Pp. 157 a 177)

Ceccato, Daniela (2016) Cuerpos encriptados: entre el ser real e irreal (Pp. 179 a 192)

Garabieta, Leonardo (2016) Cuerpo y tiempo (Pp. 193 a 201)

Gómez del Río, Gabriela (2016) Nuevos soportes, nuevos cuerpos (Pp. 203 a 217) Matarrese, Marina (2016) Cestería pilagá: una aproximación desde la estética al cuerpo (Pp. 219 a 229)

Puppo, Cecilia (2016) El arte de diseñar nuestro cuerpo (Pp. 231 a 242)

Roffe, Solana (2016) Ingeniería y arquitectura de la Moda: el cuerpo rediseñado (Pp. 243 a 253)

Ruiz, Laura (2016) Imágenes de la otredad. Arte, política y cuerpos residuales en Daniel Santoro (Pp. 255 a 265)

Suárez, Viviana (2016) Cuerpos: utopías de lo real (Pp. 267 a 284)

Avelar, Suzana (2016) El futuro de la moda: una discusión posible (Pp. 285 a 297)

Costa Sirlene M, Costa, Silgia A. (2016) Residuos agro-industriales utilizados como materias-primas en estudios de desarrollo de fibras textiles (Pp. 299 a 309)

Dantas Mendes, Francisca (2016) Diseño como estrategia de Postponement en la MVM (Pp. 311 a 328)

Ferreira Pires, Beatriz (2016) Cuerpo trazado. Contexturas orgánicas e inorgánicas (Pp. 329 a 339)

Garcia Vicentini, Cláudia Regina (2016) El lugar de la creatividad en el desarrollo de productos de moda contemporáneo (Pp. 341 a 351)

\section{b)- Congresos / Coloquios / Plenarios}

$2^{\circ}$ Plenario de Directores de Investigación DC, 27 y 4 de septiembre - 2018. En este segundo plenario los Directores de las Líneas y Proyectos de Investigación presentaron a sus pares y al conjunto del Programa de Investigación de la Facultad de Diseño y Comunicación, los resultados obtenidos y/o en proceso (publicaciones y acuerdos), junto con los avances de Proyectos. La Directora de la Línea de Investigación $\mathrm{N}^{\circ} 17$ presento a sus 
pares, los resultados del Proyecto 17.1 Cine, Moda, Cuerpo, Arte y Diseño y los avances del Proyecto 17.2 Comunicación e Imagen personal $360^{\circ}$.

III Coloquio de Investigación y Desarrollo en Diseño Latino. Universidad de Palermo, 30 de julio de 2018. IX Congreso Latinoamericano de Enseñanza del Diseño. Semana Internacional del Diseño en Palermo.

En la comisión Proyecciones de la Moda se presentaron las reflexiones y avances del Proyecto 17.1 Cine, Moda, Cuerpo, Arte y Diseño y sus intenciones de un segundo proyecto de la línea.

$1^{\circ}$ Plenario de Directores de Investigación DC, 13 de octubre - 2017. Es este primer plenario los Directores de Líneas y Proyectos de Investigación presentaron a sus pares y al conjunto del Programa de Investigación de la Facultad de Diseño y Comunicación, los resultados obtenidos y/o en proceso (publicaciones y acuerdos), junto con los Proyectos. La Directora de la Línea de Investigación №17 presentó a sus pares, los principales avances del Proyecto 17.1 Cine, Moda, Cuerpo, Arte y Diseño y sus intenciones de un segundo proyecto de la línea.

II Coloquio de Investigación y Desarrollo en Diseño Latino. Universidad de Palermo, 31 de julio de 2017. VIII Congreso Latinoamericano de Enseñanza del Diseño. Semana Internacional del Diseño en Palermo.

En la comisión Proyecciones de la Moda se presentaron las reflexiones y avances del proyecto 17.1 Cine, Moda, Cuerpo, Arte y Diseño y sus intenciones de un segundo proyecto de la línea.

I Coloquio de Investigación y Desarrollo en Diseño Latino. Universidad de Palermo, 26 de Octubre de 2016.

Se presentó la Línea de Investigación №17: Imagen, Moda y Tendencias, como una de las líneas que integran el Programa de Investigación en Diseño de la Facultad de Diseño y Comunicación.

Doria, Patricia (Argentina) Presentación de los avances de la Línea de Investigación No17: Imagen, Moda y Tendencias. Facultad de Diseño y Comunicación, Universidad de Palermo.

\section{c)- Formación de Posgrado e Impacto curricular}

La Directora Patricia Doria forma parte del Cuerpo Académico de la Facultad de Diseño y Comunicación e incorpora los contenidos se su investigación a sus asignaturas. 


\begin{abstract}
Research Project 17.1 explores different productions linked with an emphasis on cinema, as another way of narrating and temporalizing fashion. Cinema, as an expression of mass culture, has always been a representation of diverse imaginations and aspirations, where fashion, as a social and cultural phenomenon, has not been exempt from its influence. It proposes to awaken awareness of the relationship between fashion and film, and to generate new questions about these disciplinary areas, the link with the system of meanings, in the semantic and syntactic analysis that creates meaning through costumes. Extend the linguistic analysis to the set of cultural phenomena, mainly about fashion and social signs that make it possible to decode them through cinema. In this way, inspiring costumes, symbols and implicit messages come together in films that reflect values, meanings, features of times and situations anchored in the collective memory. The phenomenon is analyzed through a plural and multidisciplinary methodological journey, based on a film corpus, which establishes its correlation with the fashion system of the twentieth and twenty-first centuries.
\end{abstract}

Keywords: Audiovisual - Cinema - Corporal - Fashion - Characters - Seduction - Meaning.

Resumo: O Projeto de Pesquisa 17.1 explora diferentes produções vinculadas à ênfase no cinema, como outra forma de narrar e temporalizar a moda. O cinema, como expressão da cultura de massa, sempre foi uma representação de imaginações e aspirações diversas, onde a moda, como fenômeno social e cultural, não ficou isenta de sua influência. Propõese despertar a consciência sobre a relação entre moda e cinema, e gerar novos questionamentos sobre essas áreas disciplinares, o vínculo com o sistema de significados, na análise semântica e sintática que cria sentido por meio do figurino. Estender a análise linguística ao conjunto dos fenômenos culturais, principalmente sobre a moda e os signos sociais que permitem decodificá-los por meio do cinema. Dessa forma, figurinos inspiradores, símbolos e mensagens implícitas se unem em filmes que refletem valores, significados, características de tempos e situações ancorados na memória coletiva. O fenômeno é analisado por meio de um percurso metodológico plural e multidisciplinar, a partir de um corpus cinematográfico, que estabelece sua correlação com o sistema de moda dos séculos XX e XXI.

Palavras chave: Audiovisual - Cinema - Corporal - Moda - Personagens - Sedução - Significado.

[Las traducciones de los resúmenes fueron realizadas a través de traductor automático] 